\title{
Status iodium pada anak usia sekolah berdasarkan ekskresi iodium urin dan asupan iodium
}

Iodine status in school-age children determined from iodine urine excretion and iodine intake

Widya Ayu Kurnia Putri' ${ }^{1}$, Dodik Briawan², Hidayat Syarief ${ }^{2}$, Leily Amelia²

${ }^{1}$ Program Studi Ilmu Gizi, Fakultas Ilmu-Ilmu Kesehatan, Universitas Jenderal Soedirman, Purwokerto

${ }^{2}$ Departemen Gizi Masyarakat, Fakultas Ekologi Manusia, Institut Pertanian Bogor

\begin{abstract}
Background: School-age children are more at risk if they experience deficiencies and excess iodine. The concentration of iodine in urine is a good biomarker for assessing iodine intake, $90 \%$ of iodine intake will be excreted through urine. Objective: This study aimed to analyze the iodine status of school-age children based on urinary iodine excretion (UIE) and iodine intake. Method: The study design used a cross sectional study on 44 healthy school-aged children in Bogor Regency. Subject selection was done purposively in healthy $5^{\text {th }}$ grade elementary school students. The data taken in this study was urine iodine excretion concentration and food recall (1x24 hours). Data analysed using descriptive analysis and Pearson correlation test. Results: Median iodine excretion concentration in urine was $157 \mu \mathrm{g} / \mathrm{l}$ and the average daily iodine intake of children was $83.29 \mathrm{mg} /$ day. Conclusion: The concentration of iodine excretion in the urine of the children are in the category sufficient iodine as recommended by WHO/ UNICEF / ICCID while the daily intake of iodine for children is still in the less category. The results showed that there was no association of iodine daily intake with iodine excretion concentration in urine $(p=0.469)$.
\end{abstract}

KEY WORDS: children; intake; iodine; UIE

\section{ABSTRAK}

Latar belakang: Anak usia sekolah lebih berisiko mengalami kekurangan dan kelebihan iodium. Konsentrasi iodium dalam urin merupakan biomarker yang baik untuk menilai asupan iodium, $90 \%$ dari asupan iodium akan di eksresi melalui urin. Tujuan: Penelitian ini bertujuan menganalisis status iodium anak usia sekolah berdasarkan eksresi iodium urin (UIE) dan asupan iodium. Metode: Desain penelitian menggunakan cross sectional study pada 44 anak usia sekolah yang sehat dan dilaksanakan di Kabupaten Bogor. Pemilihan subjek dilakukan secara purposive pada siswa sekolah dasar sehat kelas 5. Pengambilan data yang dilakukan dalam penelitian ini adalah konsentrasi ekskresi iodium urin dan food recall (1x24 hours). Data di analisis menggunakan analisis deskriptif dan uji korelasi Pearson. Hasil: Median konsentrasi ekskresi iodium dalam urin sebesar $157 \mu \mathrm{g} / \mathrm{l}$ dan rerata asupan harian iodium anak sebesar 83,29 mg/hari. Simpulan: Konsentrasi ekskresi iodium dalam urin anak-anak berada dalam kategori cukup sesuai rekomendasi WHO/UNICEF/ICCID sedangkan asupan harian iodium anak masih dalam kategori kurang. Hasil penelitian menunjukan bahwa tidak ada hubungan asupan harian iodium dengan konsentrasi ekskresi iodium dalam urin $(\mathrm{p}=0,469)$.

KATA KUNCI: anak; asupan; iodium; eksresi iodium urin

Korespondensi: Widya Ayu Kurnia Putri, Program Studi Ilmu Gizi, Fakultas Ilmu-Ilmu Kesehatan, Universitas Jenderal Soedirman, Purwokerto; e-mail: widya.putri@unsoed.ac.id 


\section{PENDAHULUAN}

Iodium merupakan komponen penting yang diperlukan untuk sintesis hormon tiroid yang terutama diperoleh melalui asupan. Kecukupan iodium pada anak perlu diketahui sebab iodium berperan penting dalam mengatur metabolisme dan diperlukan untuk perkembangan terutama perkembangan saraf(1). Hampir 266 juta anak usia sekolah di seluruh dunia memiliki asupan iodium yang tidak cukup (2). Survei global iodium tahun 2011 menunjukan bahwa meskipun kecukupan iodium di seluruh dunia mengalami perbaikan, tetapi 29,8\% anak usia sekolah masih belum mencukupi (3).

Ekskresi iodium dalam urin (UIE) adalah indikator yang sensitif dari asupan iodium populasi dan merupakan indikator yang telah direkomendasikan oleh World Health Organization (WHO) untuk menilai dan memantau status iodium populasi $(4,5)$. Perkiraan asupan iodium pada tahun 2007, berdasarkan data UIE WHO dari 130 negara, 91,1\% merupakan anak usia sekolah (6). Anak usia sekolah merupakan kelompok penduduk yang bisa menggambarkan keseluruhan populasi. Hal ini dapat dilihat dari beberapa survei iodium dilakukan pada anak usia sekolah.

United Nations Children's Fund(UNICEF), WHO, dan the International Council for the Control of Iodine Deficiency Disorders (ICCIDD) merekomendasikan asupan iodium harian sebesar $150 \mu \mathrm{g}(7,8)$. Asupan iodium dari populasi tertentu umumnya dinilai dengan mengukur konsentrasi eksresi iodium dalam urin (UIE). Indikator yang direkomendasikan untuk mengukur status iodium populasi adalah median konsentrasi iodium urin (UIE) dan asupan iodium dianggap cukup ketika UIE sebesar 100-199 $\mu \mathrm{g} / \mathrm{L}$ (8). Konsentrasi eksresi iodium dalam urin diukur menggunakan sampel urin sewaktu dari sampel yang representatif yang merupakan metode yang direkomendasikan untuk menilai status iodium pada populasi (8).

Persentase nilai urine iodine excretion (UIE) pada anak usia 6-12 tahun pada tahun 2013 di Indonesia ditemukan sebesar 14,9\% yang kekurangan iodium dan 30,4\% kelebihan iodium (9). Konsekuensi kekurangan iodium ringan secara klinis kurang jelas terlihat pada anak, tetapi efek dari kurangnya iodium ringan mulai terlihat ketika anak tumbuh dewasa seperti gangguan mental yang mengarah pada kurangnya produktivitas di sekolah dan berkurangnya kemampuan intelektual (10-12). Penelitian yang dilakukan pada anak-anak usia sekolah dengan defisiensi iodium ringan sampai sedang dapat meningkatkan kognitif ketika asupan iodium meningkat (13). Sementara itu, asupan iodium yang berlebihan terkait dengan peningkatan tingkat autoimunitas tiroid dan disfungsi tiroid. Beberapa daerah di Amerika Serikat yang memiliki asupan iodium yang cukup dapat juga ditemukan adanya kelebihan iodium (14). Dengan demikian, penelitian ini bertujuan untuk menganalisis status iodium dari ekskresi iodium dalam urin dan asupan harian iodium pada anak usia sekolah.

\section{BAHAN DAN METODE}

Desain penelitian yang digunakan adalah crosssectional. Pemilihan tempat berdasarkan data tahun 2013 di Kabupaten Bogor yaitu di kelurahan dengan garam kurang beriodium. Subjek berjumlah 44 anak berusia 8-10 tahun. Data subjek yang dikumpulkan berupa data jenis kelamin, usia, konsumsi iodium, dan eksresi iodium dalam urin menggunakan urin sewaktu. Data konsumsi pangan diperoleh melalui 1x24 hours food recall, asupan iodium dianalisis menggunakan food nutrient database Australia tahun 2001-2013 (AUSNUT). Rata-rata jumlah asupan iodium dibandingkan dengan estimated average requirement (EAR) iodium anak usia 10-12 tahun (15). Subjek yang berpartisipasi dalam penelitian ini diminta untuk mengumpulkan urin sewaktu yang dikumpulkan pada pagi hari dengan wadah tertutup dan bersih, penjelasan pengumpulan urin diberikan sebelum subjek mengumpulkan urin. Urin sewaktu yang telah terkumpul diambil sebanyak $10 \mathrm{cc}$ untuk dianalisis di laboratorium. Evaluasi status iodium anak menggunakan kriteria epidemiologi WHO berdasarkan pada median konsentrasi eksresi iodium dalam urin (UIE) dari anak usia sekolah.

Proses pengolahan data meliputi kegiatan editing, coding, entry, dan cleaning menggunakan program Microsoft Excel 2010 dan SPSS versi 22.0. Analisis deskriptif dilakukan pada data karakteristik responden meliputi usia, jenis kelamin, data konsumsi iodium, dan data eksresi yodium urin. Hubungan asupan iodium dan eksresi iodium urin dianalisis menggunakan uji korelasi 
Pearson. Penelitian ini telah mendapat persetujuan etik dari Komisi Etik Penelitian Kesehatan Fakultas Kesehatan Masyarakat Universitas Diponegoro dengan nomor 271/EC/FKM/2015.

\section{HASIL}

Median konsentrasi ekskresi iodium dalam urin sebesar $157 \mu \mathrm{g} / \mathrm{l}$. Median konsentrasi ekskresi iodium dalam urin pada kelompok laki-laki dan perempuan masing-masing yaitu $148 \mu \mathrm{g} / \mathrm{l}$ dan $161 \mu \mathrm{g} / \mathrm{l}$, tetapi tidak berbeda secara statistik konsentrasi ekskresi iodium dalam urin berdasarkan jenis kelamin $(\mathrm{p}=0,600)$. Demikian juga tidak ditemukan perbedaan antara kelompok usia 9-10 tahun dan 11-12 tahun $(p=0,512)$ (Tabel 1). Berdasarkan rerata konsentrasi ekskresi iodium dalam urin, jumlah subjek dengan asupan iodium kurang $(<100 \mu \mathrm{g} / \mathrm{l})$, asupan iodium cukup (100-199 $\mu \mathrm{g} / \mathrm{l})$, dan asupan iodium lebih ( $\geq 200 \mu \mathrm{g} / \mathrm{l})$, masing masing sebesar 11 (25\%), 22 (50\%), dan 11 (25\%) (Tabel 2).

Rerata dan median asupan iodium masing-masing sebesar 73,11 mg/hari dan 83,29 mg/hari (Tabel 3).

Tabel 1. Median dan rerata konsentrasi eksresi iodium dalam urin berdasarkan jenis kelamin dan usia

\begin{tabular}{|c|c|c|c|c|}
\hline Variabel & $\mathbf{n}$ & $\begin{array}{r}\text { Median } \\
(\mu \mathrm{g} / \mathrm{l}) \\
\end{array}$ & $\begin{array}{r}\text { Rerata } \\
(\mu \mathrm{g} / \mathrm{I})\end{array}$ & Range \\
\hline \multicolumn{5}{|l|}{ Usia (tahun) } \\
\hline $9-10$ & 19 & 119 & 136,3 & $32-245$ \\
\hline $11-12$ & 25 & 164 & 152,12 & $22-236$ \\
\hline Total & 44 & 157 & 145,3 & $22-245$ \\
\hline \multicolumn{5}{|l|}{ Laki-laki (tahun) } \\
\hline $9-10$ & 5 & 65 & 84,20 & $47-164$ \\
\hline $11-12$ & 8 & 169 & 172,63 & $116-236$ \\
\hline Total & 13 & 148 & 138,62 & $47-236$ \\
\hline \multicolumn{5}{|c|}{ Perempuan (tahun) } \\
\hline $9-10$ & 14 & 167 & 154,93 & $32-245$ \\
\hline $11-12$ & 17 & 161 & 142,47 & $22-221$ \\
\hline Total & 31 & 161 & 148,1 & $22-245$ \\
\hline
\end{tabular}

Rerata asupan harian iodium pada kelompok laki-laki dan perempuan masing-masing yaitu $73,18 \mathrm{mg}$ /hari dan $87,53 \mathrm{mg} /$ hari, tetapi tidak terdapat perbedaan secara statistik asupan harian iodium berdasarkan jenis kelamin $(p=0,406)$. Demikian juga tidak terdapat perbedaan asupan harian iodium antara kelompok usia 9-10 tahun dan 11-12 tahun $(\mathrm{p}=0,327)$. Berdasarkan rerata asupan iodium, ditemukan lebih banyak (72,7\%) jumlah subjek dengan asupan iodium kurang $(<100 \mathrm{mg} /$ hari) daripada subjek dengan asupan iodium cukup (27,3\%) (Tabel 4). Hasil uji korelasi Pearson menunjukan tidak ada hubungan asupan harian iodium dengan konsentrasi ekskresi iodium dalam urin $(\mathrm{r}=0,112 ; \mathrm{p}=0,469)$.

\section{BAHASAN}

Studi ini menunjukkan bahwa median konsentrasi ekskresi iodium dalam urin pada anak-anak usia sekolah adalah $157 \mu \mathrm{g} / \mathrm{l}$. Menurut nilai median tersebut menunjukkan bahwa daerah yang dipilih dalam penelitian ini bukan merupakan daerah endemik gangguan akibat kekurangan iodium (GAKI). Hal ini didukung oleh data konsentrasi ekskresi iodium dalam urin bahwa sebesar 50\% dari anak-anak memiliki status iodium cukup. Rerata asupan harian iodium anak sebesar 83,29 mg/hari. Penelitian yang dilakukan dengan menggunakan data survei yang dilaksanakan di semua provinsi (33 provinsi) di Indonesia dan semua kabupaten/kota menggunakan sampel Survei Sosial Ekonomi Nasional (SUSENAS) menunjukkan sebesar 13\% nilai UIE anak usia sekolah kurang dari $100 \mu \mathrm{g} / \mathrm{L}$ dan 22\% memiliki risiko kelebihan iodium dengan nilai UIE lebih $300 \mu \mathrm{g} / \mathrm{L}$ (16).

Hasil penelitian ini, 25\% dari subjek menunjukkan asupan iodium kurang berdasarkan konsentrasi ekskresi iodium dalam urin. Demikian juga sebagian besar anak $(72,7 \%)$ memiliki rerata asupan iodium yang tergolong kurang. Hormon tiroid penting untuk metabolisme,

Tabel 2. Distribusi konsentrasi eksresi iodium dalam urin pada anak usia sekolah

\begin{tabular}{lrrrr}
\hline & \multicolumn{3}{c}{ Median $(\boldsymbol{\mu g} / \mathbf{l})$} & \multirow{2}{*}{ Total } \\
\cline { 2 - 4 } & $<\mathbf{1 0 0} \boldsymbol{\mu g} / \mathbf{l}(\mathbf{\%})$ & $\mathbf{1 0 0 - 1 9 9} \boldsymbol{\mu g} / \mathbf{l}(\mathbf{\%})$ & $\mathbf{2 0 0} \boldsymbol{\mu g} / \mathbf{l}(\mathbf{\%})$ & \\
\hline Laki-laki & $4(30,8)$ & $7(53,8)$ & $2(15,4)$ & $13(29,5)$ \\
Perempuan & $7(22,6)$ & $15(48,4)$ & $9(29)$ & $31(70,5)$ \\
Total & $11(25)$ & $22(50)$ & $11(25)$ & $44(100)$ \\
\hline
\end{tabular}


Tabel 3. Median dan mean asupan harian iodium berdasarkan jenis kelamin dan usia

\begin{tabular}{lrrrr}
\hline \multicolumn{1}{c}{ Variabel } & $\mathbf{n}$ Median & Rerata & \multirow{2}{*}{ Range } \\
\cline { 3 - 4 } & & $(\boldsymbol{\mu g} / \mathbf{l})$ & $(\boldsymbol{\mu g} / \mathbf{l})$ & \\
\hline Usia (tahun) & & & & \\
9-10 & 19 & 76,30 & 88,90 & $44,19-157,8$ \\
11-12 & 25 & 71,44 & 79,03 & $41,38-147,46$ \\
Total & 44 & 73,11 & 83,29 & $41,38-157,8$ \\
Laki-laki (tahun) & & & & \\
9-10 & 5 & 72,52 & 83,16 & $53,26-151,22$ \\
11-12 & 8 & 57,93 & 66,94 & $41,38-114,96$ \\
Total & 13 & 61,29 & 73,18 & $41,38-151,22$ \\
Perempuan (tahun) & & & & \\
9-10 & 14 & 78,18 & 90,95 & $44,19-157,8$ \\
11-12 & 17 & 74,64 & 84,72 & $44,54-147,46$ \\
Total & 31 & 76,30 & 87,53 & $44,19-157,8$ \\
\hline
\end{tabular}

pertumbuhan, dan perkembangan organ khususnya otak, kebutuhan hormon tiroid meningkat khususnya pada anak sekolah. Produksi yang tidak memadai hormon tiroid disebut gangguan kekurangan iodium (IDDs) (17). Oleh karena itu, banyak negara berusaha keras mencegah gangguan defisiensi iodium dengan penggunaan garam beriodium. Secara global, 68\% dari rumah tangga memiliki akses terhadap garam beriodium (6). Sebanyak 37 dari 128 negara memiliki cakupan iodium garam, 90\% dari rumah tangga mengonsumsi garam beriodium yang memadai dan secara keseluruhan $70 \%$ dari rumah tangga di seluruh dunia memiliki akses terhadap garam beriodium (3). Berdasarkan penelitian yang dilakukan di Kecamatan Getasan menunjukkan bahwa persentase garam rumah tangga yang memenuhi SNI 30 ppm KIO3 masih rendah $(<50 \%)$ dengan median UIE $93 \mu \mathrm{g} / \mathrm{L}$ yang termasuk dalam kategori kekurangan iodium (18). Rumah tangga yang telah menggunakan garam beriodium sebesar $86 \%$ dan $62,3 \%$ rumah tangga menggunakan garam mengandung cukup iodium (16).

Asupan iodium lebih $(\geq 200 \mu \mathrm{g} / \mathrm{l})$ dalam penelitian ini berdasarkan konsentrasi ekskresi iodium dalam urin ditemukan pada $25 \%$ anak. Kelebihan asupan iodium dapat berakibat sama seperti jika kekurangan iodium yaitu hipertiroidisme, tiroiditis autoimun, hipotiroidisme, dan gondok. World Health Organization menganjurkan asupan harian iodium yang direkomendasikan yaitu $90 \mu \mathrm{g}$ untuk anak-anak berusia 1-8 tahun, $120 \mu \mathrm{g}$ untuk anakanak berusia 9-13 tahun, dan $150 \mu \mathrm{g}$ untuk anak-anak
Tabel 4. Distribusi asupan harian iodium pada anak usia sekolah

\begin{tabular}{|c|c|c|c|}
\hline & \multicolumn{2}{|c|}{ Rerata (mg/hari) } & \multirow[b]{2}{*}{ Total (\%) } \\
\hline & $\begin{array}{r}<100 \mathrm{mg} / \mathrm{hari} \\
(\mathrm{n}, \%)\end{array}$ & $\begin{array}{r}\geq 100 \mathrm{mg} / \mathrm{hari} \\
(\mathrm{n}, \%)\end{array}$ & \\
\hline Laki-laki & $11(84,6)$ & $2(15,4)$ & $13(29,5)$ \\
\hline Perempuan & $21(78,7)$ & $10(32,3)$ & $31(70,5)$ \\
\hline Total $(\%)$ & $32(72,7)$ & $12(27,3)$ & $44(100)$ \\
\hline
\end{tabular}

berusia lebih dari 14 tahun (19). Paparan kronis asupan iodium yang tinggi dikaitkan dengan perkembangan gondok, peningkatan kadar serum thyrotropin, perubahan volume tiroid, dan pengembangan antibodi tiroid (20-21).

Banyak negara cukup asupan iodium, beberapa laporan menunjukkan bahwa asupan iodium lebih ditemukan di beberapa daerah dan negara, seperti Jepang, Cina, dan India (20,22-24). Nilai median dari UIE yang tinggi ditemukan pada $16 \%$ anak-anak sekolah di Jepang (23). Survei UIE yang dilakukan pada 130 negara melaporkan bahwa 31,5\% anak mengalami defisiensi iodium. Lebih lanjut, sebanyak 47 negara menunjukkan defisiensi iodium dan 7 negara memiliki status iodium yang berlebih (6).

Penelitian ini menyimpulkan bahwa asupan harian iodium tidak berhubungan dengan konsentrasi ekskresi iodium dalam urin. Penelitian sebelumnya menunjukan bahwa asupan iodium tidak mempengaruhi UIE subjek penelitian, tingginya kadar iodium dalam tanah dan air dalam penelitian tersebut mungkin dapat mempengaruhi UIE subjek (25). Selain itu, konsentrasi iodium dalam tanaman pangan tergantung pada iodium dalam tanah sebagai tempat tanaman pangan tersebut tumbuh (26).

\section{SIMPULAN DAN SARAN}

Studi ini menunjukkan median konsentrasi ekskresi iodium dalam urin anak sebesar $157 \mu \mathrm{g} / \mathrm{l}$ dan rerata asupan harian iodium anak sebesar 83,29 mg/hari. Konsentrasi ekskresi iodium dalam urin anak berada dalam kategori cukup iodium sesuai yang direkomendasikan oleh WHO/ UNICEF/ICCID sedangkan asupan harian iodium anak masih dalam kategori kurang. Tidak ditemukan hubungan antara asupan harian iodium dengan konsentrasi ekskresi iodium dalam urin $(\mathrm{p}=0,469)$. Perlu dilakukan pemantauan status iodium anak karena defisiensi dan 
kelebihan iodium memiliki dampak yang sama. Selain itu, perlu adanya penelitian lebih lanjut mengenai asupan iodium karena dalam penelitian ini menggunakan food nutrient database Australia tahun 2001-2013 (AUSNUT) sehingga perlu adanya database iodium bahan makanan yang ada di indonesia agar kandungan iodium dalam asupan pangan di Indonesia dapat dilihat dengan tepat.

\section{UCAPAN TERIMA KASIH}

Penulis mengucapkan terimakasih kepada Nestle Foundation yang telah mengizinkan penulis bergabung dan menggunakan beberapa data dalam penelitian besar yang berjudul "Nutrition promotion for improving iodine status of children at iodine endemic area in West Java, Indonesia".

\section{Pernyataan konflik kepentingan}

Penulis menyatakan tidak ada konflik kepentingan dengan pihak-pihak yang terkait dalam penelitian ini.

\section{RUJUKAN}

1. Delange F. The role of iodine in brain development. Proc Nutr Soc. 2000;59(1):75-9. doi: 10.1017/s0029665100000094

2. de Benoist B, McLean E, Andersson M, Rogers L. Iodine deficiency in 2007: global progress since 2003. Food Nutr Bull. 2008;29(3):195-202. doi: $10.1177 / 156482650802900305$

3. Andersson M, Karumbunathan V, Zimmermann MB. Global iodine status in 2011 and trends over the past decade. J Nutr. 2012;142(4):744-50. doi: 10.3945/ jn.111.149393

4. Zimmermann MB. Iodine deficiency. Endocr Rev. 2009;30(4):376-408. doi: 10.1210/er.2009-0011

5. Andersson M, Takkouche B, Egli I, Allen HE, de Benoist B. Current global iodine status and progress over the last decade towards the elimination of iodine deficiency. Bull World Health Organ. 2005;83(7):518-25.

6. Pearce EN, Andersson M, Zimmermann M. Global iodine nutrition - where do we stand in 2013?. Thyroid. 2013;23(5):523-8. doi: 10.1089/thy.2013.0128

7. Food and Nutrition Board, Institute of Medicine. Dietary reference intakes. Washington DC: National Academy Press; 2006.

8. World Health Organization. Assessment of iodine deficiency disorders and monitoring their elimination: a guide for programme managers, 3rd ed. Geneva: WHO; 2007.
9. Kementerian Kesehatan RI. Laporan hasil riset kesehatan dasar (Riskesdas) tahun 2013. Jakarta: Badan Penelitian dan Pengembangan Kesehatan, Republik Indonesia; 2013.

10. Gordon RC, Rose MC, Skeaff SA, Gray AR, Morgan KM, Ruffman T. Iodine supplementation improves cognition in mildly iodine-deficient children. Am J Clin Nutr. 2009;90(5):1264-71. doi: 10.3945/ajen.2009.28145

11. Santiago-Fernandez P, Torres-Barahona R, Muela-Martinez JA, Rojo-Martinez G, Garcia-Fuentes E, Soriguer F, et al. Intelligence quotient and iodine intake: a crosssectional study in children. J Clin Endocrinol Metab. 2004;89(8):3851-7. doi: 10.1210/jc.2003-031652

12. Zimmermann MB, Connolly K, Bozo M, Bridson J, Rohner F, Grimci L. Iodine supplementation improves cognition in iodine-deficient school children in Albania: a randomized, controlled, double-blind study. Am J Clin Nutr. 2006;83(1):108-14. doi: 10.1093/ajen/83.1.108

13. Zimmermann MB. Iodine deficiency and excess in children: worldwide status in 2013. Endocr Pract. 2013;19(5):839-46. doi: 10.4158/EP13180.RA

14. Chung HR. Iodine and thyroid function. Ann Pediatr Endocrinol Metab. 2014;19(1):8-12. doi: 10.6065/ apem.2014.19.1.8

15. Gibson RS. Principles of nutritional assessment, second edition. New York (NY): Oxford University Press; 2005.

16. Kartono D, Samsudin M, Supadmi S. Asupan iodium anak sekolah di Indonesia. Gizi Indon. 2014;33(1):8-19.

17. Zimmermann MB. Iodine deficiency and excess in children: worldwide status in 2013. Endocr Pract. 2013;19(5):839-46. doi: 10.4158/EP13180.RA

18. Kartono D, Samsudin M, Supadmi S. Perkiraan asupan iodium dan natrium menggunakan urin 24 jam pada anak dan dewasa. Media Gizi Mikro Indonesia. 2014;5(2):7184.

19. Saggiorato E, Arecco F, Mussa A, Sacerdote C, Rossetto R, Origlia C, et al. Goiter prevalence and urinary iodine status in urban and rural/mountain areas of Piedmont region. J Endocrinol Invest. 2006;29(1):67-73. doi: 10.1007/ BF03349179

20. Duarte GC, Tomimori EK, de Camargo RY, Catarino RM, Ferreira JE, Medeiros-Neto G, et al. Excessive iodine intake and ultrasonographic thyroid abnormalities in school children. J Pediatr Endocrinol Metab. 2009;22(4):327-34. doi: 10.1515/jpem.2009.22.4.327

21. Zimmermann MB, Ito Y, Hess SY, Fujieda K, Molinari L. High thyroid volume in children with excess dietary iodine intakes. Am J Clin Nutr. 2005;81(4):840-4. doi: 10.1093/ ajcn/81.4.840

22. Zou Y, Lou X, Ding G, Mo Z, Zhu W, Zhou J, et al. An assessment of iodine nutritional status and thyroid hormone levels in children aged 8-10 years living in Zhejiang 
Province, China: a cross-sectional study. Eur J Pediatr. 2014;173(7):929-34. doi: 10.1007/s00431-014-2273-y

23. Fuse Y, Saito N, Tsuchiya T, Shishiba Y, Irie M. Smaller thyroid gland volume with high urinary iodine excretion in Japanese school children: normative reference values in an iodine sufficient area and comparison with the $\mathrm{WHO} /$ ICCIDD reference. Thyroid. 2007;17(2):145-55. doi: 10.1089/thy.2006.0209

24. Kapil U. Excess iodine nutrition in Delhi. Indian Pediatr. 2010;47(10):894.
25. Madukosiri CH, Esther I. Iodine content in diet and urine of people in imiringi and otuasega communities in Ogbia Lga, Bayelsa. Electronic Journal of Environmental, Agricultural and Food Chemistry. 2011;10(5):2216-21.

26. Pehrsson PR, Patterson KY, Spungen JH, Wirtz MS, Andrews KW, Swanson CA, et al. Iodine in food- and dietary supplement-composition databases. Am J Clin Nutr. 2016;104(Suppl 3):868S-76S. doi: 10.3945/ ajcn.115.110064 